\title{
AFINAL,
}
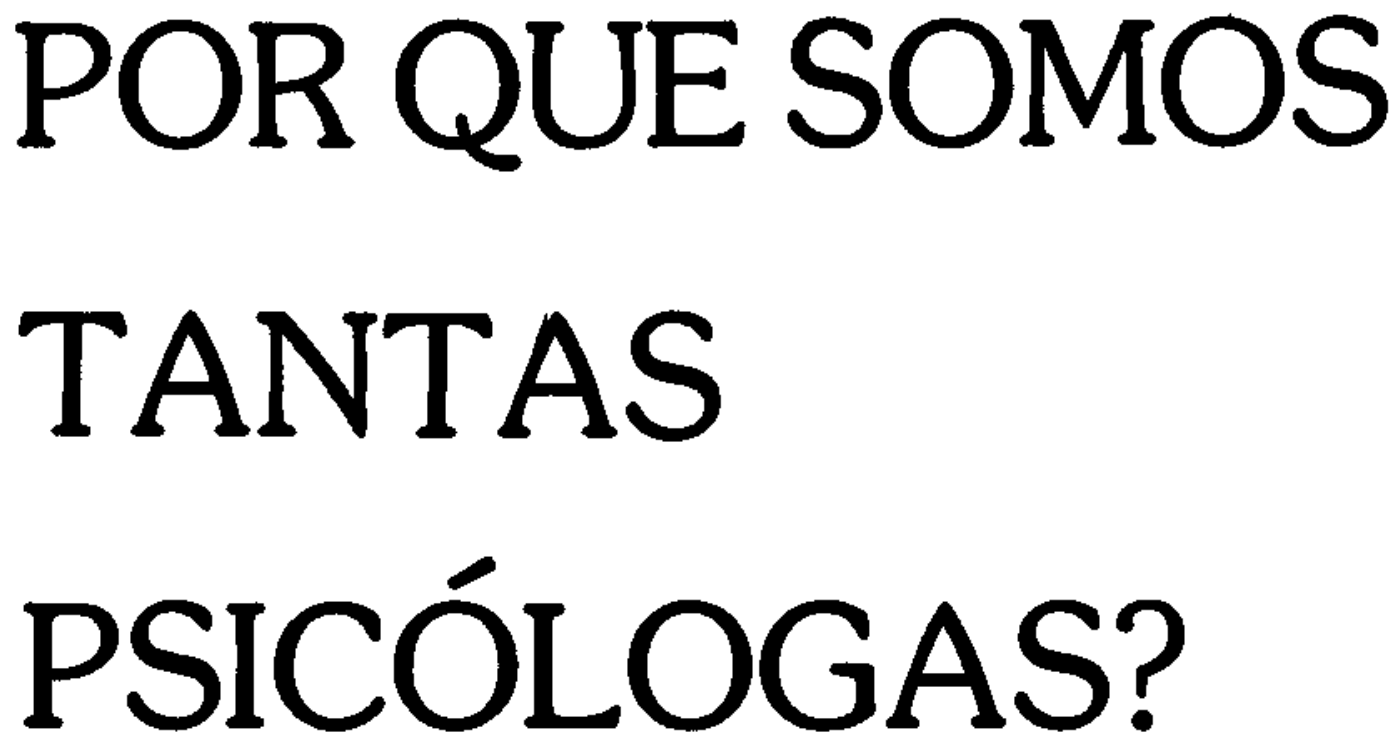

\section{Fúlvia Rosemberg}

Pesquisadora do Departamento de Pesquisas Educacionais da Fundaçao Carlos Chagas

Acho que decidi fazer psicologia quando tinha 16 anos. Devia estar cursando o $1 .^{\circ}$ ou $2 .^{\circ}$ clássico. E certo que uma orientaçắo humanística já havia sido feita: como tantas outras adolescentes, com 14 anos tinha "escolhido" o clássico. A razăo desta 1." "decisáo" foi confusa, mas me lembro de argumentos meus e dos outros do tipo: "A Fúlvia nâo dá para Matemática". Outras irmăs (e mesmo minha matel antes de mim, já apontavam a direção: uma normalista e outra cursando direito. Entre os meninos, meus irmáos, as opçסes foram mais diversificadas: científico, clássico, seminário.

Como gostava de estudar e năo me via trabalhando logo, acho que por isso recusei o normal. Fui parar, entáo, no clássico, iniciando um longo conviver em gueto sexual: no clássico éramos provavelmente 30 mulheres e uns 5 homens. No cursinho, năo consigo me lembrar de rapazes: em plena adolescência, de tendência heterossexual marcada, vibrante de sensualidade, os rostos de colegas de que me lembro săo todos femininos. Continuei pertencendo à maioria feminina na faculdade, no doutoramento. Hoje, no Departa. mento de Pesquisas Educacionais, para 18 pesquisadoras do quadro apenas um homem.

Pela metade do curso clássico discutíamos a opçáo por uma faculdade. Nao sei bem se era carreira. Nunca foi questionado que continuaria estudando, que faria faculdade. Mas qual? Como postura consciente, tenho idáia de ter feito cursinho para psicologia por exclusăo. Năo queria fazer direito (problemas de identificaçá com a irma mais velha?), não queria seguir magistério. Dançando, num baile de formatura, na época, retive uma cena - Meu par, querendo me apertar, propondo o rosto colado que eu recusava, dizendo num sussurro excitante: "talvez fazendo psicologia vocé entenda por que năo quer se encostar em mim!".

Com ou sem sexualidade reprimida, me preparei conscientemente para o vestibular. Disciplinas: Português, Inglês, Francês, Filosofia e... Matemática. Como troféu da época, e a contradiçấo da minha vida acadêmica e profissional: mesmo náo sendo "dotada para raciocínio matemático", estudaria Matemática no cursinho, de igual para igual, com um candidato à engenharia do ITA, tirei 9 na prova escrita de Matemática, passei sem oral nos exames de estatística durante o curso de psico. logia (com o professor SEVERO, tradicional por seu rigor), sou pesquisadora, gosto de demografia e orientei essa minha discussăo através de alguns marcos numéricos.

$O$ ponto de partida foi um con. vite da Associaçao Profissional dos Psicólogos de Minas Gerais para que participasse da mesa redonda "Psicologia Profissåo Feminina". 


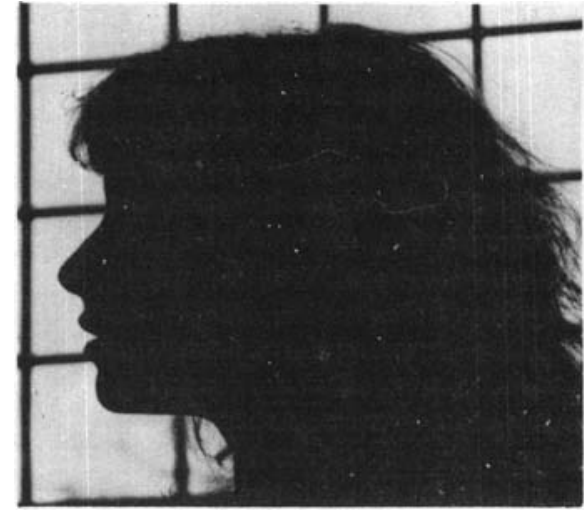

Quem trabalha com estatística educacional já enfrenta problemas: veracidade e continuidade dos dados, estabilidade nas definiçóes de categorias, atualidade e disponibilidade das publicaçóes contendo dados secundários. Quem trabalha com dados secundários à luz da variável sexo enfrenta problema duplo, pois, a despeito das inúmeras recomendaçōes nacionais e internacionais, as estatísticas sobre a educaçáo brasileira, nos últimos anos, e no que diz respeito à variável sexo, são omissas, avaras e sexistas. Ou o dado náo é coletado (por exemplo, desde 1974 os dados nacionais processados sobre ensino superior não discriminam mais a variável sexol, ou ele é coletado parcimoniosamente, apenas para uma categoria e năo para outra (tem-se dado discriminado por sexo para corpo docente e não dis. cente no ensino superior) ou entăo ele é coletado usando como referência implicita (isto é, como normal e modelar) a trajetória de vida escolar masculina.

Estas imperfeiçōes na coleta, processamento e divulgaçăo dos dados refletem-se na organização deste texto, que às vezes assume a forma de uma colcha de retalhos nacional. $\mathrm{Na}$ ausência de um dado para uma região usei de outra e vice-versa.

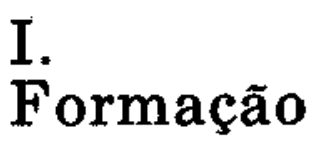

A última década observou três fenômenos importantes relativos ao ensino superior:

1. sua expansão;

2. a maior expansão do setor privado em detrimento do públi- co, devido principalmente "ao incentivo dado à criação de pequenas escolas isoladas particulares, as quais não possuindo condiçoes de investir em outras áreas, optavam, na maioria das vezes, pelos cursos de humanidades" (SESU, 1980:2);

3. e finalmente uma importante expansāo da matrícula feminina, que de minoritária em 1971 $(41,5 \%)$, já sobrepujava a masculi. na no meio do decênio (DEI. SO/IBGE, 1979:325).

A psicologia contribui, com sua parcela, para configurar esta estrutura da universidade brasi. leira. Expandiu na década, graças ao setor privado e também, em parte, à participaçảo da mulher. Assim é que a nivel nacional, os 28 cursos de psicologia em 1971, passaram a 51 em 1977. No Estado de São Paulo em 1970 existiam 5 cursos particulares e 4 públicos; em 1979 continuavam a existir os mesmos 4 cursos públicos porém. os particulares passaram a 20 !

A terceira contribuiçáo - de uma expansăo das matrículas femininas - é possível entendè-la, no caso da psicologia, de duas formas complementares. De um aldo, o próprio fato de os cursos de psicologia terem aumentado no período mencionado - e sendo a psicologia um curso "escolhido" principalmente por mulheres - já indicaria uma contribuição da psicologia para a expansão das matrículas de mulheres no ensino superior. Por outro, de acordo com informaçoes sobre o vestibular do CESGRANRIO no periodo compreendido entre 1973 e 1977 estaria também ocorrendo um aumento da "escolha" feminina pelo vestibular de psicologia. Com efeito, H. Lewin (1977) estudando o padrão de escolhas masculinas e femininas pelas carreiras oferecidas pelo vestibular CESGRANRIO observou que PSICOLOGIA obtém uma taxa de feminilidade superior a $80 \%$ e que essa taxa passou de $80,5 \%$ em 1973 para $86,0 \%$ em 1977.

Em resumo, a formação universitária em psicologia poderia quase que se constituir em micromodelo do que ocorreu com o ensino superior na década; expansăo, expansão graças à rede particular e absorvendo um grande número de mulheres.

Já ultrapassamos a euforia do milagre brasileiro. A cada dia que obviedade me intrigou: afinal, por que somos tantas psicólogas? 
passa, o cotidiano vem-nos mos. trando que certas expansóes sắo falaciosas e nāo atestam uma melhoria da condiçấo de vida. Esta expansāo das matrículas femininas no ensino superior está longe de suscitar euforia e alardes. E importante que se tente compreendé-la. Se é verdade que, de acordo com observaçoes de Glaura Miranda (1975), as mulheres portadoras de diploma universitário têm mais chance de serem absorvidas pelo mercado de trabalho, é verdade também que a abertura do ensino superior às mulheres, ao invés de diversificar - leque de carreiras possiveis, manteve a dicotomizaçáo entre carreiras masculinas e femininas. E sabe-se que no mercado de trabalho a dicotomizaçăo masculinafeminina corresponde também a carreiras consideradas mais privilegiadas (engenharia, por exemplo) e menos privilegiadas (ramos da filosofia, enfermagem e... psicologia).*

\section{II. \\ Mercado de Trabalho}

No fim da década de 70 e no início de 80 foram realizadas as duas pesquias anteriormente citadas sobre nosso perfil profissional: a da Associaçāo Profissional dos Psicólogos do Distrito Federal (datada de 79 ), que se baseia nas informaçōes prestadas por 355 psicólogos atuantes no Distrito Federal; a do Sindicato dos Psicólogos do Estado de Săo Paulo, e do Conselho Regional de Psicolo. gia, realizada pelo DIEESE em 1981 e que se apoiou em 500 entrevistas fornecidas por 500 psicólogos da Grande Sao Paulo e do interior do Estado (20 cidades).

Muitos dos dados coletados e interpretados nessas duas pesquisas refletem perfeitamente a situaçăo da mulher no mercado de

\footnotetext{
* A pesquisa eobre o perfil profissional do psicólogo do Distrito Federal (Borges. Andrade, 8/d), indica essa mesma tendencia: "Os percentuais dos pos-graduados que trabalham săo mais elevados que 0 percentual $(80,9 \%$ ) dos psicólogos (em geral) exercendo sua profissao." (pśs. 32).
}

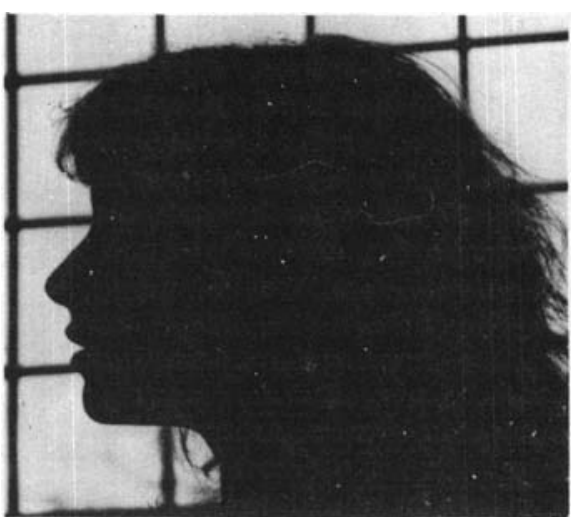

trabalho. Ou seja, a psicologia pa. rece năo constituir uma carreira desviante no que diz respeito às discriminaçठes sofridas pela mulher: remuneraçåo inferior à mas. culina; remuneraça complemen. tar à renda familiar; número de horas de trabalho fora de casa inferior ao do homem; encargos familiares que competem com a atuaçăo profissional; dificuldades de absorcáo pelo mercado de tra. balho (vide quadro).

Ora, quando esta situaçáo profissional é integrada à formaçăo universitária, parece que estamos diante de um paradoxo, ou pelo menos de uma indagaçáo: por que tantas mulheres continuam a frequentar um curso, que năo é gratuito, para enfrentar este mercado de trabalho, que as rejeita na proporçăo de $1 / 3$ e que quando as aceita oferece-lhes uma remuneraçăo tāo pouco gratificante?

Objetivamente 0 relatório da

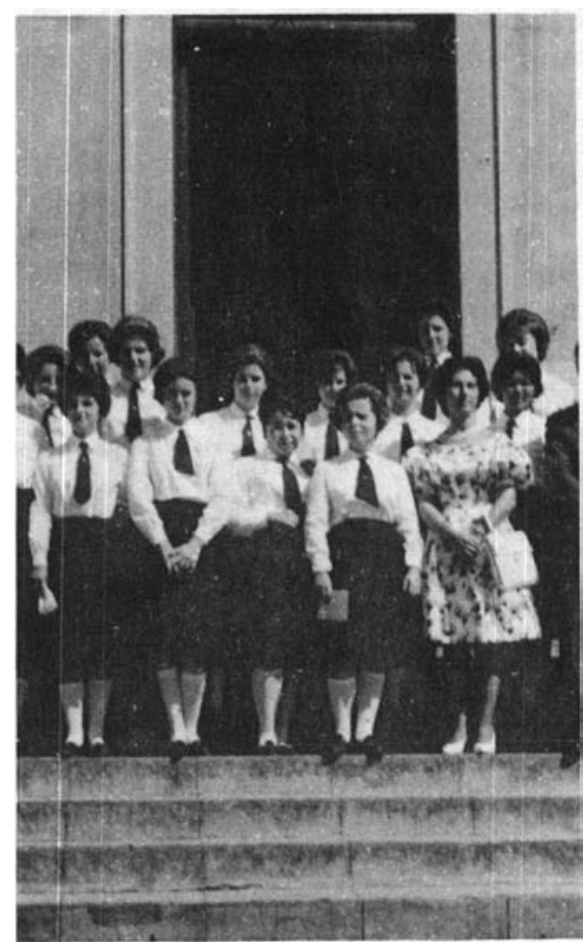

pesquisa de Săo Paulo interpreta o paradoxo da seguinte forma: "Globalmente, os dados aqui apresentados colocam em evidên. cia a questao do compromisso entre a formação académica e $\quad$ exercicio da profissão, que năo apresentam relaçáo estreita para o conjunto da categoria, uma vez que razoável parcela da categoria nåo trabalha como psicólogo, e o tempo de ingresso em atividade profissional é, para boa proporçăo da categoria, posterior ao momento de formatura." Gostaria, po. rém, de propor um avanço na interpretaçăo integrando-a à condiçăo feminina.

Por trás do espanto refletido na frase citada existe, talvez, uma aceitaçåo implícita (e que é de muitos nós) da teoria do capital humano, brilhante e jocosamente reinterpretada por Salm (1980) através da frase: há quem trate a escola como um departamento de pessoal do mercado de trabalho. Os dados observados sobre a formaçāo e situação profissional do psicólogo nos estāo mostrando que a possibilidade de incorporaça de um indivíduo no mercado de trabalho ultrapassa de muito a sua formaçảo educacional, entendida como capacitaçăo ou como credenciamento. $\mathbf{E}$ isto $\dot{e}$ tanto mais evidente quando se pensa comparativamente na escolaridade de homens e mulheres. Por uma série de indicadores (sobre os quais poderei voltar mais tarde) frequentar a escola parece desem. penhar funçঠes diferentes na vida de homens e mulheres. Pode-se mesmo supor que frequentar escola e obter um diploma nảo sejam a mesma coisa para as mulheres. Mas, ainda que a escola ainda poderia estar desempenhando para as mulheres a funçăo de guarda e proteçăo, de modo semelhante aos conventos no século XVIII.

Portanto, esta defasagem entre altos custos de formaça (tempo de permanência na escola, tensāo proveniente de competiçäo, gastos com pagamento das mensalidades, de transporte e outros) e pequenos (ou năo tảo altos) benefícios profissionais tende a nos mostrar que, provavelmente, as mulheres estăo fruindo o frequentar um curso de psicologia através de outros circuitos que não obrigatoriamente aqueles possíveis pelo mercado de trabalho. Este descompasso entre formaçấo e trabalho profissional só aparente. 
mente se constitui em anomia, pois ao contrário poderia estar mostrando um bom potencial de adaptação das mulheres às condiçōes concretas de vida, em família, na escola e no mercado de trabalho.

\section{III. \\ Uma \\ Tentativa de Compreensão}

Dito de forma mais explícita, pode-se pensar também que as mulheres continuam a "escolher" o curso de psicologia (como outras carreiras ditas femininas) pela eficiência do processo de socializaçāo no reforçamento de modelos de papéis sexuais dicotomizados; pelo serviço que essa formaçāo dicotomizada vem prestando à manutenção de uma estrutura de empregos segregacionista; e pelos benefícios imediatos que traz a uma população de mulheres necessitando ainda conciliar sua dupla perspectiva de vida e que no concreto de seu cotidiano implica. rá ou uma opção afetivamente frustradora ou a dupla jornada de trabalho. Retomarei cada um des. tes pontos tentando explicitá-los mais adequadamente.

O reforço dos modelos sexuais tradicionais: Uma plêiade de estu. dos relativamente recentes em Psicologia vem sugerindo que a socialização diferencial dos sexos, reservando à mulher um papel expressivo e ao homem um papel instrumental, acarreta limitaçoes nas expectativas e motivações femininas quanto a seu desempenho na vida adulta.

O impacto que causaram as constataçōes de Horner (1968) sobre o medo do sucesso, presente e comum entre mulheres inteligentes, indica o quanto ainda somos ignorantes sobre os mecanismos psicológicos profundos conseqüentes a uma socialização dividi. da entre a maternidade $\mathrm{e} o$ trabalho profissional, e que constituem freios formidáveis à vontade de inovação. A absorção, melhor seria mesmo dizer a impregnação, deste modelo tradicional e ambíguo se efetua para além dos muros domésticos, estando pre-

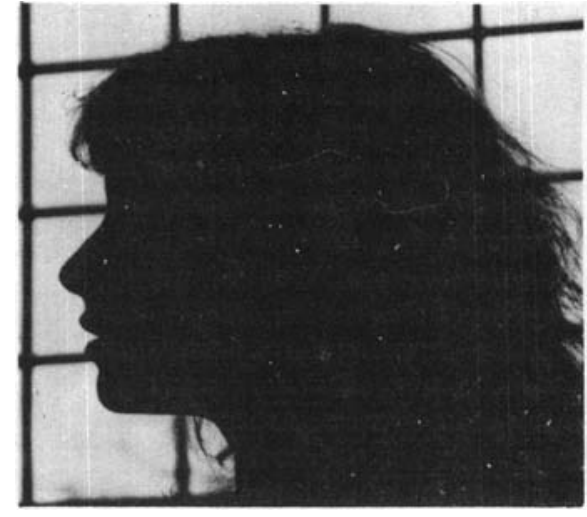

sente na rua, na igreja, nos meios de comunicação, na escola. Inclusive nos cursos de psicologia.

A atuação da escola como reprodutora da ideologia dominante tem sido frequentemente denunciada por todos aqueles que visam à construção de uma sociedade democrática. No campo específico da reprodução de modelos sexjs. tas, a bibliografia norte. americana e européia vem desmontando pouco a pouco as engrenagens escolares responsáveis pela transmissão de modelos sexuais bipolarizados. Tem-se, entāo, informaçâo sobre a existência de padrōes sexistas na interaçāo entre professores e alunos, que, mesmo sendo de natureza incons. ciente, não apenas refletem os va. lores discriminatórios da socieda. de abrangente, mas também se originam da própria cultura esco. lar. A situação de sala de aula, necessitando e exigindo comportamento obediente dos alunos, tenderia a reforçar estes mesmos componentes sexistas criados e reforçados por outras instituiçōes.

Apesar do interesse que grupos de professores vềm demonstrando em conhecer e em melhorar a condiçāo das mulheres, năo existe, a nosso conhecimento, nenhuma proposta oficial de inclusão deste tema no currículo de normalistas ou nas disciplinas didáticas de nível superior quando se teria, entăo, condição de refletir sobre a própria discriminaçấo sofrida, bem como sobre a atua. ção enquanto reforçadoras de tais padroes.

Além da denúncia, da descriçăo dos mecanismos psicológicos e dos programas anti-sexistas no campo da interação professor. aluno, pesquisadores de paises europeus e norte-americanos têm encontrado fortes indicios da existência de discriminação con- tra a mulher nos currículos e nos materiais didáticos utilizados em todos os níveis escolares, desde o pré-primário até a universidade.

No Brasil, as pesquisas visan. do a denunciar a existência de uma cultura sexista na escola têm-se dedicado principaimente à análise de textos didáticos. $E$ os resultados brasileiros têm sido idênticos aos denunciados no Ex. terior: o material didático utilizado na escola veicula uma imagem dos papéis sexuais bipolarizada, valorizando o sexo masculino, apresentando-o como o representante da espécie humana; no seu canto, a mulher, principalmente adulta, é tida como ser inferior, passiva, dependente do homem, restringindo sua vida à esfera do doméstico, à maternidade.

Se os mecanismos psicológicos envolvidos na interaçáo humana podem ter significado afetivo mais profundo que currículos e materiais didáticos, estes, por sua vez, têm a vantagem da flexibilidade por se tratar de material sim. bólico. Deste modo, se a menina e a jovem encontram no seu cotidiano poucos modelos alternativos concretos de mulheres desviantes das carreiras tradicionais, curriculos e materiais didáticos podem oferecer modelos simbólicos, abrindo em muito o leque das informaçбes disponiveis.

$E$ importante que se tenha consciência da extraordinária penetraçāo dos valores sexistas nas manifestaçðes do saber oficial, isto é, o utilizado e recomendado pela escola: dicionários de língua pátria omitem verbetes sobre profissỏes nāo tradicionalmente femininas (por exemplo, engenheira, pesquisadora) e manuais de pediatria recomendam que na idade pré-puberal "haverá maior diversificaçáo dos exercícios físicos para o sexo feminino e para o mas. culino; para aquele, buscam desenvolver a graça e o ritmo do movimento, enquanto para este exigem movimentos mais amplos, flexíveis e resistentes; têm também caráter higiênico." (Alcântara, p. 141).

Se os exemplos que escolhi po. dem ser criticáveis pela quase jocosidade que encerram, a questăo não deixa de ser bastante grave: os centros produtores e difusores de conhecimento não alcançaram a questão da discriminaçāo contra a mulher ao nivel de um problema 
exigindo sua eliminaçáo, o que, sabemos, só ocorrerá se a sociedade civil se mobilizar. Inclusive a académica. Inclusive através da própria revisăo dos conhecimen. tos acumulados. Inclusive e principalmente os do ámbito da psico. logia.

Năo sabemos da existência de qualquer recomendaçăo, no passado a no presente, visando a combater as discriminaçoes sexuais em curriculos e materiais didáticos. E as comissoes curricu. lares em suas recomendaçסes existiram e continuam a existir, vigilantes à mais leve oposiçăo aos valores tradicionais. Mais grave ainda é que organismos oficiais (MOBRAL, FENAME e INL) produzem e/ou coeditam e/ou distribuem material didático veiculando imagens ultrapassadas, tradicionais, discriminadoras e, por vezes, mesmo preconceituosas contra a mulher. E os cursos de psicologia acabam também por veicular teorias psicológicas ideologicamente enviesadas e respaldadas no conhecimento científico, tido por muitos como neutro e objetivo, isto é, acima de qualquer suspeita. Aqui, gostaria de dar destaque à postura que a psicologia fcom algumas exce-

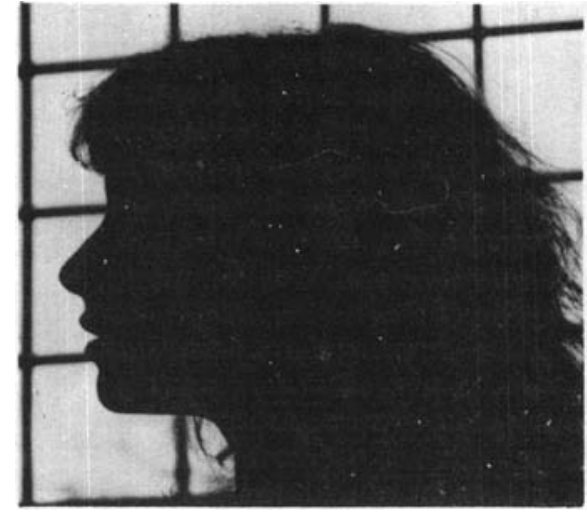

coes), enquanto corpo de conhecimento, tem dado à questăo da maternidade, reforçando e criando componentes ideológicos sobre o trabalho feminino e consequentemente avaliando as formas alternativas de cuidado e educaçăo de criança pequena.

A ideologia da "finalidade da 'mulher matura se esgota na maternidade" ou "a máe é do filho como o filho é da máe" encontrou um aliado muito importante no especilista da infância - higienistas, médicos, psicólogos. Se os médicos depositaram na máe a principal responsabilidade pela saúde física da criança, os "psi" responsabilizaram-se pela saúde mental. $O$ modelo ideal e saudável, o único modelo adequado de educação da criança pequena é no interior da díade. $\mathbf{E}$ mais ainda. $\mathbf{A}$ maternidade é a redençåo da mulher se nos ativermos a certos textos de Freud, de seus seguidores e vulgarizadores (Badinter, 1980; Ehrenreich \& English, 1979).

Se por um lado a maternidade realiza a mulher, por outro lado a evoluçăo da criança em termos psicológicos depende dessa mesma mulher: e aí um outro grupo de psicólogos é responsável pela amarração ideológica definitiva. Spitz e Bowlby introduzindo o conceito da sindrome do hospitalismo, jogaram a suspeita definitiva sobre a educaçăo e guarda da criança pequena em qualquer outra instituiçăo que náo seja a familia.

Os trabalhos sobre as carências psicológicas de crianças criadas em instituiçðes vieram fechar - círculo: de um lado colocar a família como instituiçăo nâo só adequada como a única normal para educação da criança; exacerbar, por outro, o sentimento de culpa da māe, usando como canal de divulgaçăo poderoso os meios de comunicação de massa. A família, em especial a mãe, săo os melhores, se năo os únicos seres adaptados e adequados para criar

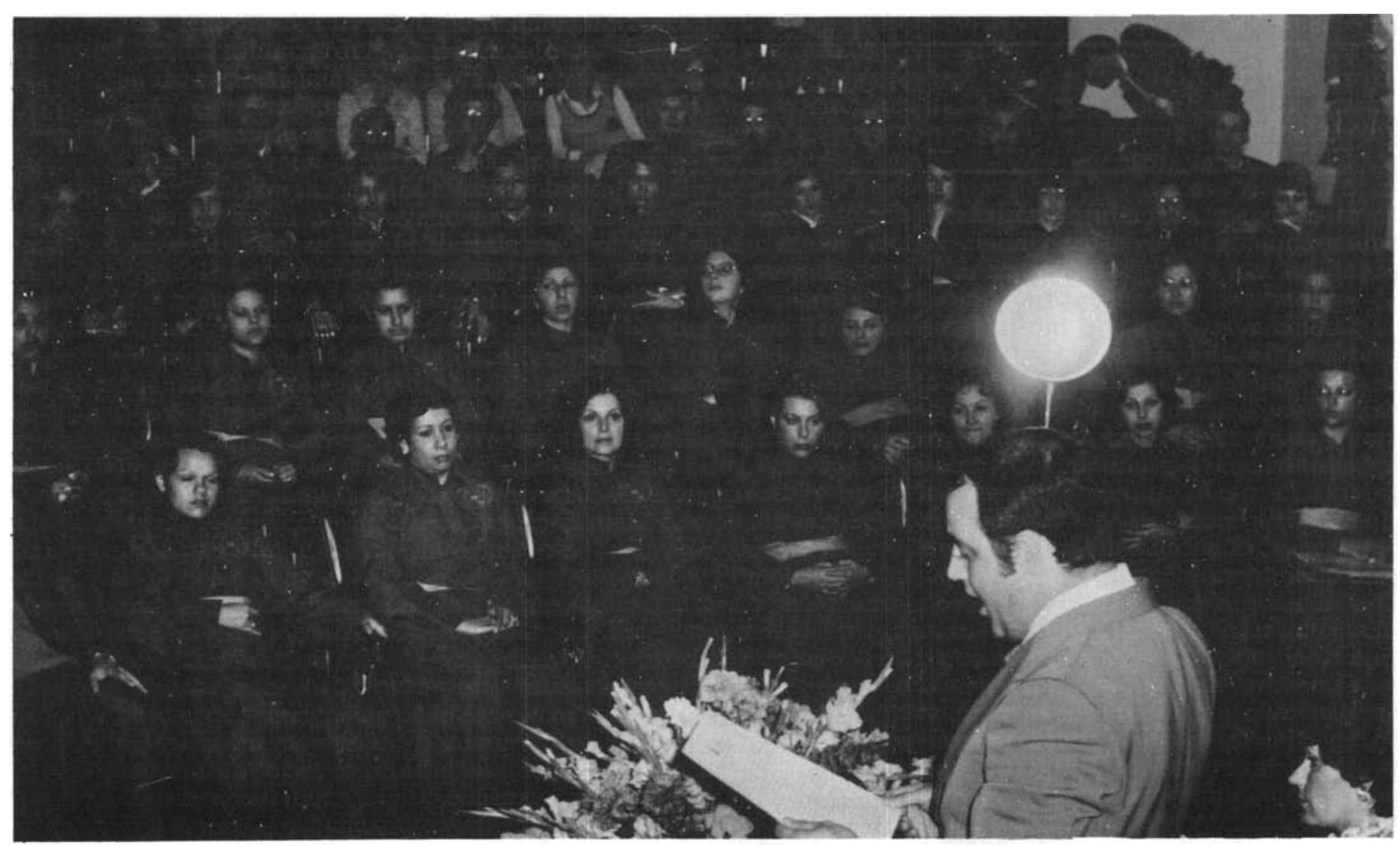


a criança pequena: essa mãe "natural" $\mathrm{e}$ "instintivamente" preparada para esta função năo é porém apta, necessitando do reforço do especialista. Especialista que vai interpondo-se, como intermediário importante, na relaçāo entre a mãe e a criança.

Como consequência direta sobre a instituição creche, a família passa a ser o modelo que deve ser imitado. A creche passa a ser aceita apenas como substituta da mấe. Para escapar ao estigma da instituição (que se associa a imagens de abandono, desamor, carência) a creche se cola ao modelo familiar e se propōe a uma substituição. Substituiçâo pesada em

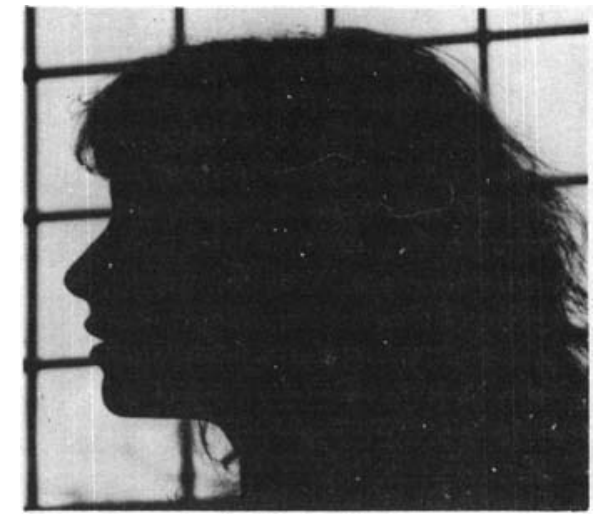

consequâncias: para a mảe, para o pessoal que nela trabalha e conseqüentemente para a criança.

A persistência de discrimina-

PESQUISAS

\begin{tabular}{|c|c|c|}
\hline & $\begin{array}{l}\text { ESTADO DE } \\
\text { SĀO PAULO }\end{array}$ & $\begin{array}{l}\text { DISTRITO } \\
\text { FEDERAL }\end{array}$ \\
\hline $\begin{array}{l}A N O D E \\
C O L E T A D E \\
D A D O S\end{array}$ & 1981 & 1979 \\
\hline Mulheres & $88 \%$ & $76 \%$ \\
\hline Casados & $53 \%$ & $62 \%$ \\
\hline Idade & $\begin{array}{l}90 \% \text { menos de } 40 \\
\text { anos }\end{array}$ & $\begin{array}{l}66 \% \text { entre } 25 \text { e } 34 \\
\text { anos }\end{array}$ \\
\hline Tem filho & $43 \%$ & - \\
\hline $\begin{array}{l}\text { Situação } \\
\text { Profissional }\end{array}$ & $\begin{array}{l}86 \% \text { trabalham fora } \\
66 \% \text { trabalham fora } \\
\text { como psicólogas } \\
60 \% \text { trabalham co- } \\
\text { mo psicólogos no } \\
\text { local de trabalho } \\
\text { principal }\end{array}$ & $\begin{array}{l}77 \% \text { não possuem } \\
\text { rendimentos como } \\
\text { autônomos } \\
46 \% \text { não são assa- } \\
\text { lariados } \\
40 \% \text { têm rendi- } \\
\text { mentos de outras } \\
\text { atividades exceto } \\
\text { psicologia }\end{array}$ \\
\hline Remuneração & $\begin{array}{l}\text { Remuneração } \\
\text { média } \\
\text { Aproximadamente } \\
6,5 \text { salários mini- } \\
\text { mos } \\
\text { Abaixo da média: } \\
60 \%\end{array}$ & $\begin{array}{l}\text { Maioria dos assa- } \\
\text { lariados recebe } \\
\text { entre } 7 \text { e } 9 \text { salários } \\
\text { mínimos }\end{array}$ \\
\hline Carga Horária & $\begin{array}{l}78 \% \text { das mulherese } \\
48 \% \text { dos homens } \\
\text { trabalham até } 40 \\
\text { horas semanais }\end{array}$ & - \\
\hline $\begin{array}{l}\text { Cursaram } \\
\text { Faculdade Particular }\end{array}$ & $85 \%$ & $68 \%$ \\
\hline
\end{tabular}

çōes sexuais na escola é ainda reforçada, no caso brasileiro, pela ausência quase que absoluta de materiais alternativos. A nāo ser alguns raros livros de lazer recentemente publicados que se preocupam em propor modelos femininos alternativos aos tradicionais, a professora brasileira năo dispòe de instrumental de apoio, semelhante ao que existe em outros países do mundo. A revisăo crítica da psicologia, no plano de igualdade entre os sexos, tem ficado quase que exclusivamente restrita ao militantismo feminista, o que vale dizer, pouco acessivel. Acessibilidade esta ainda restrin. gida pelo fato de a reflexăo brasileira no setor ser escassa, devendo-se recorrer a textos estrangeiros com as conseqüentes barreiras de custo e língua.

A escola também reforça diretamente nos alunos os padrōes tradicionais pela própria estrutura hierárquica de cargos e funçóes que propicia, aos homens, postos superiores aos das mulheres. Tendo diante de si modelos femininos simbólicos e reais tradicionais, a menina, a moça e a mulher adulta têm pouca possibilidade de trilhar desvios, de sair do habitual. Complementarmente, 0 estudante de sexo masculino também deixa de conviver com modelos femininos divergentes, o que pode enrijecer suas percepçōes e expectativas quanto ao desempenho de homens e de mulheres. Essa situação se vê agravada pelo fato de que a segregaçāo observada entre alunos se mantém no corpo docente: mulhe. res tendem a ser com maior fre. qưencia professoras de cursos fre. qüentados por mulheres.

A menos que se desenvolva uma açăo, também no plano escolar, que vise à transformaçāo da condiçāo feminina, as reformas preocupadas apenas com a expansão do ensino contribuirāo para reforçar os papéis tradicionais de homens e mulheres.

A segregaça ocupacional: Bruschini (1979), estudando a forca de trabalho masculina e feminina nāo-agrícola, observa que sua distribuiçáo se processa desigualmente por entre ocupaçőes e setores de atividade, ocorrendo verdadeira segregaçāo ocupacional por sexo. De um lado, a participaçầo masculina se distribui relativamente bem por entre as ocupaçōes 
e os setores de atividade, ao passo que a feminina se concentra em empregos domésticos, de professora, enfermeira ou balconista (pág. 13). Esta segregação provoca, segundo a mesma autora, "o surgimento de um "mercado de trabalho dual' que permite explicar as diferenças de salário entre homens e mulheres em termos da análise da oferta e da procura" (pág. 18). A pesar de pouco signifi. cativa a contribuição das mulheres universitárias no cómputo geral da taxa de participação da mu. lher na força de trabalho, sua colocaçao em carreiras educacionais (professorado e afins) é bastante alta, tendo dobrado nas duas últjmas décadas (pág. 19).

A segregação observada na formação secundária, universitária, se mantém geralmente durante a vida profissional, com desvantagens evidentes no mercado de trabalho.

Acreditar que o desenvolvimento económico e a expansāo do ensino por si só possam corrigir o viés histórico é perpetuar uma situaçáo indesejável. Por outro lado, imaginar que apenas a açăo educacional poderia reorientar e banir as especializaçóes observadas seria ingenuidade, pois a atual estrutura do mercado de tra. balho se encarregaria de reduzir estas mulheres a desempregadas plenas.

Sabedoria da conciliaçāo ou senso da realidade: Enfrentando esta estrutura do mercado de trabalho, vivendo (e reproduzindo) o peso de discriminaçōes, sofrendo o impacto do processo de socialização durante a infáncia e a vida adulta e năo contando com o companheiro ou equipamentos coletivos com quem possa dividir as $\mathrm{li}$ des domésticas, principalmente a guarda, educação e proteçāo dos filhos pequenos, projeto e trajetória educacional da mulher tendem a divergir da masculina. Sendo dadas e mantidas as condiçōes atuais, nada mais estratégico que, tendo a possibilidade de frequientar a escola, a "opçáo" feminina seja por cursos flexíveis. Cursos - como o de psicologia - que por sua generalidade, ná. tecnicidade, nao-especialidade permitam um leque alternativo de "opçōes" profissionais mesmo que elas impliquem subemprego: professora particular, intérprete, secretária, jornalista, professora,

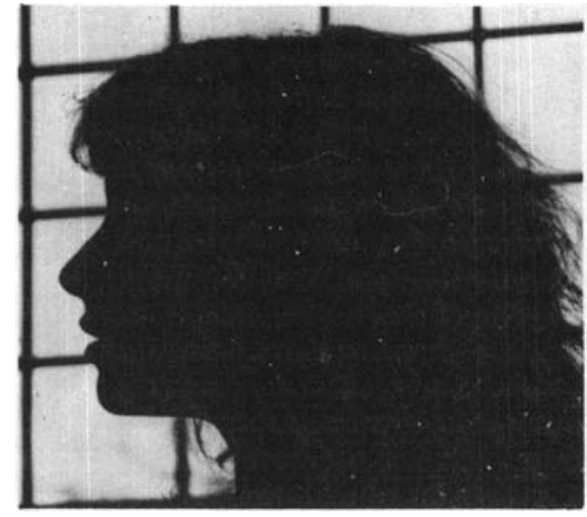

de muitas mulheres seria mais um determinante da segregaçāo edu. cacional e de sua permanência.

Modelar-se, adaptar-se, conciliar: seus processos internos sấo a margem de manobra que lhes resta para dar conta de expectativas suas que năo se esgotam na preservação da espécie humana.

O sistema escolar não é uma ilha. Também náo é neutro. Modi. ficaçōes substanciais significando igualdade de oportunidades educacionais para os sexos não ocorrem apenas pela miscegenação do ensino, pela expansão das matrículas femininas. Educação igualitária, hoje, seria aquela que, assumindo também a existência de discriminaçáo sexual se propusesse a uma açăo mobilizadora.

quzoes que levaram-nas a "esco lher" as carreiras frequentadas (Lewin, 1977 e a Bonitatibus, 1977). Cursos, enfim, que "permitam" que $1 / 3$ das pessoas forma. das (como a Psicologia) exerça uma outra atividade profissional, diferente daquela para a qual se credencionam na Universidade.

Aumentar a cultura geral pode significar tanto armazenar conhe. cimentos gerais suscetíveis de se converterem em instrumento de trabalho profissional, quanto em serem utilizados no cotidiano doméstico: enquanto mãe, enquanto esposa, enquanto pessoa não. profissional.

$\mathrm{Na}$ medida em que o futuro profissional é incerto, pois a ma. ternidade pode, independente da vontade individual ou da expectativa da mulher, impedir o prosseguimento de uma carreira profis. sional por falta quase que absolu. ta de formas alternativas de cuidado e educação do filho, procurar conhecimentos polivalentes ou reconvertiveis ao cotidiano parece-nos demonstrar o exercício de um poderoso senso de realida. de. Uma estratégia de sobrevivência. Estou querendo sugerir que moças também escolhem cursos assistenciais, ligados à área de educação ou para-médicos - co. mo a psicologia - năo apenas porque sua socialização conduziu-as a "preferirem" papéis expressivos; não apenas por seu passado escolar que privilegiou as humanidades em detrimento das ciên. cias e da técnica mas também pelo ajustamento de tais cursos à am. bivalência de sua condiçáo. A fun. cionalidade dessas especializaçoes no aqui e agora do cotidiano

\section{Bibliografia}

ALCANTARA. Pedro de \& MARCONDES, Eduardo. Pediatria básica. v. 1, 2."

BADINTER, Elisabeth. L'amour en plus: histoire de l'amour maternel. Paris, Flammarion, 1980.

BONIT ATIBUS, Suely Grant. Ensino st. pletivo no municipio de SAo Paulo: características da clientela do ensino supletivo de 1. gran.

BORGES-ANDRADE, JAIRO, E.; CUNHA, M. HELENA B.; COSTA, M. TE. REZA P. M. "Descriçăo do Psicólogo no Distrito Federal: perfil social e económico e formaçáo profissional". Mimeo. Brasília, s/d.

BOWLBY, John. Maternal care and mental health. Who Monocraphs, (2), 1952.

BRUSCHINI, Maria Cristina Aranha. "Serualizacso das ocupacses; O caso brasileiro". Cadernos de Pesquisa, Săo Paulo (28):5-20, mar., 1979.

DEISO/IBGE. Indicadores sociais: relatório 1979. Rio de Janeiro, IBGE 441 p., 1979. EHRENREICH, Barbara \& ENGLISH, Deidre. For her own good. N. York, Anchor Book, 1979.

HORNER, Matina. Sex differences in achievement motivation and performance in competitive and non-competitive situations. Michigan, University Microfilms, 1968 .

LEWIN, Helena. Diversificactio da demanda ao ensino superior; o comportamento feminino diante da carreirs nniversitária. Rio de Janeiro, Fundaçăo CESGRANRIO. 311 p., 1977.

MIRANDA, Glaura Vasques de. "A edu. caçá da mulher brasileira e sua participaçáo nas atividades económicas em 1970". Cadernos de Peaquiaa, Săo Paulo (15):2-36, dez., 1975.

SALM, Claudio L. Escola e trabalho. Sáo Paulo, Brasiliense, 112 p., 1980.

SESU/MEC. "A evoluçáo do alunado do ensino superior no Brasil 1970/1979". Boletim Informativo SESu/Brasília, 9 p., 1980.

SPITZ, Renée. Hospitalism: an inquiry into the genesis of psychiatric conditions in early childhood. Psychoanal Study Child, (1): $53.74,1945$. ed., Sáo Paulo, Sarvier, 1968. 